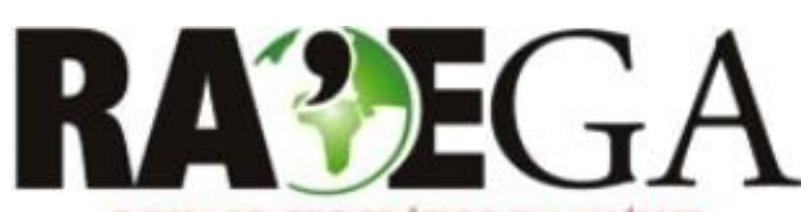

O ESPACYO GEOGRÁFICO EM ANÁLISE

\title{
ESTUDO DA ALTERAÇÃO ANTRÓPICA (HEMEROBIA) DA BACIA HIDROGRÁFICA DO RIO MOURÃO - PR
}

\section{STUDY OF ANTHROPOGENIC CHANGE (HEMEROBIA) THE BASIN OF RIVER MOURAO -PR}

\author{
Maristela Moresco Mezzomo \\ Departamento Acadêmico de Ambiental \\ Universidade Tecnológica Federal do Paraná - UTFPR \\ Campo Mourão, PR, Brasil \\ e-mail: mezzomo@utfpr.br \\ Géssica Silva Gasparini \\ e-mail: gessica.gasparini@gmail.com
}

Recebido em: 12/10/2015

Aceito em:25/01/2016

\section{Resumo}

As transformações da paisagem desenvolvidas por atividades antrópicas podem ocasionar inúmeros problemas como desequilíbrio nos ecossistemas, erosão de solos e assoreamento de rios. Uma das ferramentas para verificar a pressão das ações do ser humano na paisagem se dá por meio do conceito de hemerobia. Neste sentido, o objetivo deste artigo é apresentar o estudo de graus de dependência energética e tecnológica (hemerobia) da bacia hidrográfica do rio Mourão - PR, em relação ao ano de 2014, visando auxiliar o planejamento de ações para diminuir os riscos e impactos ambientais em relação ao solo e à água. Para isso, foram feitos a caracterização da área de estudo, o levantamento de dados e informações sobre o uso do solo e a classificação e quantificação dos graus de hemerobia utilizando a proposta de Kröker (2008). Os graus foram classificados como hemerobia mínima, muito baixa, baixa, média, alta, muito alta e máxima. A classificação da paisagem da bacia, conforme as unidades de paisagem definidas por Scipioni (2014) demonstra que três das quatro unidades possuem todos os graus de hemerobia (mínimo, muito baixo, baixo, médio, alto, muito alto, máximo). A análise quantitativa dos graus de hemerobia demonstra que $85,26 \%$ apresentam grau médio, composto por áreas utilizadas para agricultura, 


\title{
ESTUDO DA ALTERAÇÃO ANTRÓPICA (HEMEROBIA) DA BACIA HIDROGRÁFICA DO RIO MOURÃO - PR
}

pecuária, solo exposto e áreas para futuras construções, e 7,81\% representa 0 grau mínimo utilizado por Unidades de Conservação, Áreas de Preservação Permanente e fragmentos florestais. Esta classificação possibilitou identificar determinadas funções da paisagem, podendo assim, contribuir no planejamento e direcionamento de ações sobre o uso e a ocupação do solo.

Palavras-chave: Paisagem, Classificação, Planejamento.

\begin{abstract}
The landscape transformations developed by human activities can cause numerous problems such as imbalance in the ecosystems, soil erosion and silting of rivers. One of the tools to check the pressure of the actions of human beings in the landscape is through the concept of hemerobia. In this sense, the aim of this paper is to present the study of degrees of energy and technological dependence (hemeroby) in river basin Mourão-PR, for the year 2014, aiming to assist the planning of actions to reduce the risks and environmental impacts from the ground and water. For this, they were made the characterization of the study area, the data collection and information on land use and the classification and quantification of degrees of hemeroby using the proposed Kröker (2008). The grades were classified as minimum hemeroby, very low, low, medium, high, very high and maximum. The landscape classification of the basin, according to the landscape units defined by Scipioni (2014), it shows that three of the four units have all degrees of hemeroby (minimum, very low, low, medium, high, very high, maximum). The quantitative analysis of the degree hemerobia shows that $85,26 \%$ present a medium degree, composed of areas used for agriculture, livestock, soil and exposed areas for future buildings, and $7,81 \%$ is the degree minimum used by Protected Areas, Areas of Permanent Preservation and forest fragments. This classification enabled us to identify certain landscape functions and can thus contribute in the planning and direct actions on the use and land use.
\end{abstract}

Keywords: Landscape, Classification, Planning.

\section{INTRODUÇÃO}

A manutenção e desenvolvimento das atividades de ordem econômica e social da sociedade atual envolvem uma relação de dependência para com os elementos naturais e por isso, a não promoção de alterações nos sistemas ambientais e/ou o desencadeamento de impactos é praticamente impossível. Por outro lado, entende-se que é possível a diminuição e prevenção de determinadas situações ambientalmente negativas, por meio da ação planejada das atividades humanas, como no caso da identificação de potencialidades da paisagem, por meio da indicação de limites e aptidões. Esta forma de 


\section{ESTUDO DA ALTERAÇÃO ANTRÓPICA (HEMEROBIA) DA BACIA HIDROGRÁFICA DO RIO MOURÃO - PR}

pensamento pode ser aplicada em projetos diversos, como no caso de planos diretores, zoneamento ecológico econômico, planejamento ambiental municipal, plano de gestão de bacias hidrográficas e estudos que tenham como foco a paisagem.

Nesta perspectiva de indicação de limites e aptidões, a paisagem é considerada como um conjunto dinâmico e em constante evolução e que, portanto, deve ser analisada de forma integrada, com destaque para a compreensão sobre sua estrutura e dinâmica (BERTRAND, 1971).

Esta forma de compreensão da paisagem aliada à necessidade de planejamento das ações antrópicas permite que se aplique o conceito de hemerobia, compreendido como a totalidade das alterações da paisagem de acordo com graus de naturalidade (JALAS, 1955 apud TROPPMAIR, 1989).

A aplicação do conceito de hemerobia tem variado conforme os autores e objetivos dos estudos. É possível encontrar na literatura, diferentes definições para determinar a hemerobia conforme exposto no Quadro 1. O primeiro autor a apresentar o conceito de hemerobia foi Jalas (1955), que analisou o nível de antropização das paisagens, classificando-as em anemeoróbio (paisagens naturais ou com pouca interferência antrópica), oligohemeoróbio (paisagens mais naturais do que artificiais), mesohemeoróbio (paisagens mais artificiais do que naturais) e euhemeoróbio (paisagens artificiais).

Depois disso, outros autores utilizaram a interpretação de hemerobia para analisar a relação de alteração ou efeitos das ações humanas sobre as paisagens, como Sukopp (1972), Haber (1990) e Hough (1995). No Brasil, destacam-se os trabalhos de Monteiro (1978) e Fávero et al. (2004). 


\section{ESTUDO DA ALTERAÇÃO ANTRÓPICA (HEMEROBIA) DA BACIA HIDROGRÁFICA DO}

RIO MOURÃO - PR

\begin{tabular}{|c|c|c|c|}
\hline Autor & Ano & Conceitos & Classes \\
\hline JALAS & 1955 & $\begin{array}{c}\text { Hemerobia: grau de } \\
\text { artificialidade e } \\
\text { naturalidade do meio }\end{array}$ & $\begin{array}{c}\text { Ahemeorobio; } \\
\text { Oligohemeorobio; } \\
\text { Mesohemeorobio; } \\
\text { Euhemeorobio }\end{array}$ \\
\hline SUKOPP & 1972 & $\begin{array}{c}\text { Hemerobia: totalidade dos } \\
\text { efeitos das ações } \\
\text { humanas sobre a } \\
\text { paisagem }\end{array}$ & $\begin{array}{c}\text { Natural; Quase-natural; } \\
\text { Semi (agri-natural); Agri- } \\
\text { cultural; Quase cultural; } \\
\text { Cultural }\end{array}$ \\
\hline MONTEIRO & 1978 & $\begin{array}{c}\text { "Derivação antropogênica": } \\
\text { alterações na paisagem } \\
\text { causadas pelo homem }\end{array}$ & $\begin{array}{c}\text { Transformações positivas; } \\
\text { Transformaces negativas }\end{array}$ \\
\hline HABER & 1990 & $\begin{array}{c}\text { Classificação dos tipos de } \\
\text { uso da terra conforme a } \\
\text { diminuição da naturalidade } \\
\text { e o aumento da } \\
\text { artificialidade }\end{array}$ & $\begin{array}{c}\text { Bio-ecossistemas; Tecno- } \\
\text { sistemas }\end{array}$ \\
\hline HOUGH & 1995 & $\begin{array}{c}\text { Grau de interferência } \\
\text { humana na paisagem }\end{array}$ & $\begin{array}{c}\text { Paisagem formal; } \\
\text { Paisagem natural }\end{array}$ \\
\hline FÁVERO, & 2004 & $\begin{array}{c}\text { Hemerobia: avaliação das } \\
\text { unidades de paisagem } \\
\text { conforme elementos } \\
\text { naturais e interferência } \\
\text { antrópicas }\end{array}$ & $\begin{array}{c}\text { A; B; C; } \text { D E } \\
\text { (A hemerobia aumenta } \\
\text { conforme a ordem } \\
\text { crescente das letras) }\end{array}$ \\
\hline
\end{tabular}

Quadro 1: Autores e conceitos sobre hemerobia. Fonte: Freitas (2008).

Estes trabalhos têm impulsionado o desenvolvimento de diversos estudos como no caso dos trabalhos de Kröker et al. (2005) e Kröker (2008), que destacam que o conceito de hemerobia pode ser utilizado para avaliar e acompanhar as mudanças no uso e cobertura do solo que afetam os sistemas ecológicos, divididos em diferentes graus de modificações. A análise dos graus de hemerobia para os autores permite verificar, por exemplo, o estado de dependência energética e tecnológica da paisagem, podendo ser uma ferramenta utilizada para diferentes finalidades.

É nesta perspectiva de entendimento sobre hemerobia que o presente artigo foi desenvolvido, considerando graus de alteração antrópica a partir da análise do uso e cobertura do solo. O objetivo foi realizar a classificação da hemerobia tendo como área de estudo a bacia hidrográfica do rio Mourão, localizado na mesorregião centro-ocidental do Paraná e assim, contribuir de alguma forma para futuras ações de gestão da bacia ou com projetos de planejamento ambiental. A bacia hidrográfica do rio Mourão tem soma 1.814,73 


\section{ESTUDO DA ALTERAÇÃO ANTRÓPICA (HEMEROBIA) DA BACIA HIDROGRÁFICA DO \\ RIO MOURÃO - PR}

$\mathrm{km}^{2}$ e abrange parte dos municípios de Campo Mourão, Mamborê, Luiziana, Peabiru, Engenheiro Beltrão e Quinta do Sol, totalizando 141.000 habitantes (IBGE, 2010). Faz parte do sistema hidrográfico da bacia do rio Ivaí, que deságua no rio Paraná (Figura 1).

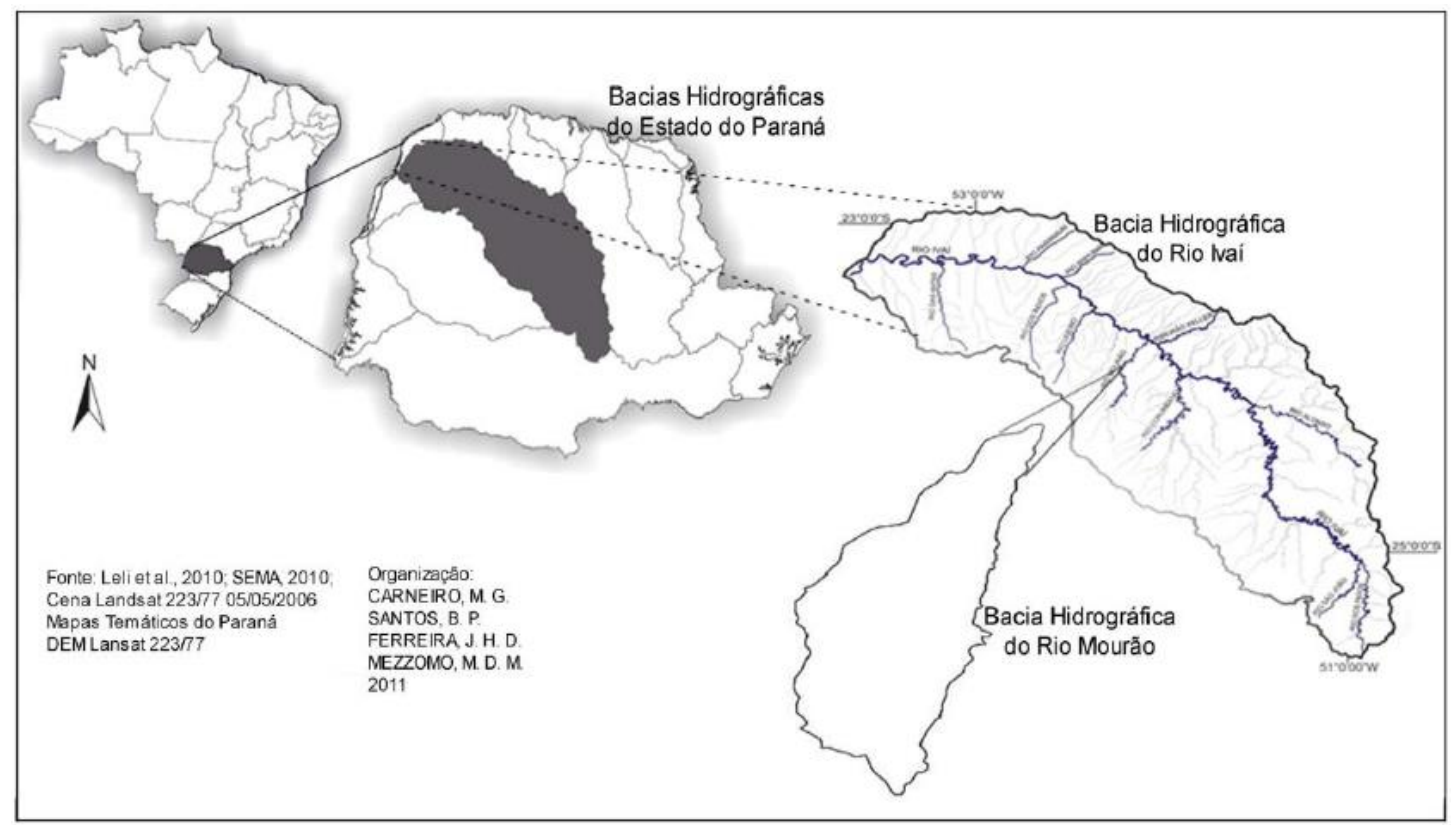

Figura 1: Croqui de localização da bacia hidrográfica do rio Mourão. Fonte: Scipioni (2014).

\section{MATERIAIS E MÉTODOS}

O estudo teve como método a abordagem sistêmica, envolvendo a análise integrada das etapas desenvolvidas, descritas no Fluxograma 1. A última etapa do estudo envolveu a determinação de graus de hemerobia com base na proposta por Rudolf Kröker (2008), com algumas adaptações. Foram adotadas como valores mínimos, as áreas de vegetação e como valores máximos áreas com construções, como por exemplo, áreas industriais. 


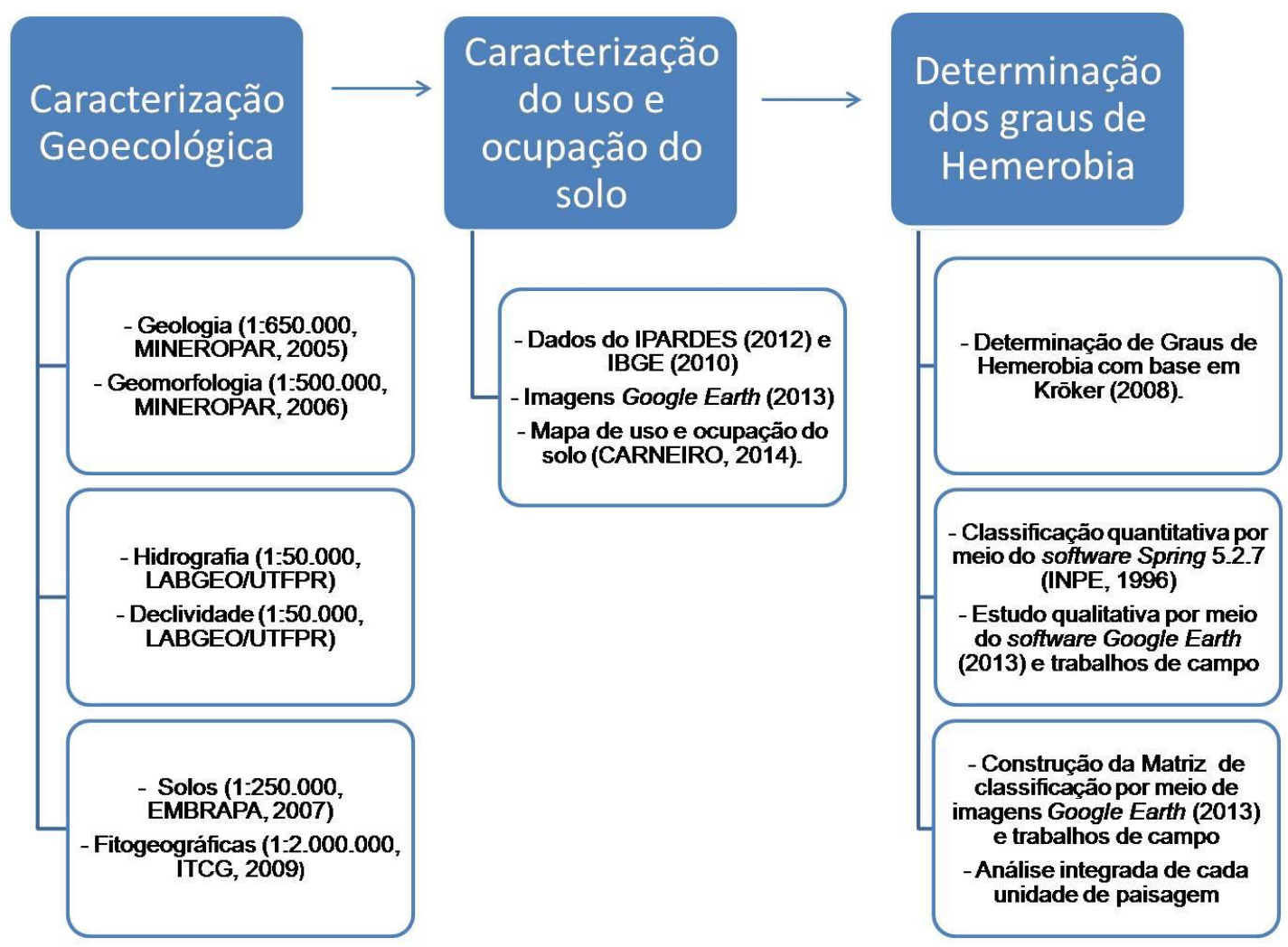

Fluxograma 1: Sequência metodológica e materiais utilizados.

Na proposta de Kröker (2008), as paisagens são divididas pelos graus de hemerobia, assim entendidas:

- paisagens com menor grau de hemerobia são as que possuem baixa dependência tecnológica e energética para a manutenção da funcionalidade; alta capacidade de auto-regularão, alto aproveitamento das funções da natureza; superfícies permeáveis; vegetação original e fauna/flora nativa.

- paisagens com maior grau de hemerobia são as que possuem alta dependência tecnológica e energética para a manutenção da funcionalidade; baixa capacidade de auto-regularão; pouca conexão com a dinâmica dos valores naturais; desenho padrão e como expressão de esmero, estética e civismo; baixa relação com as características locais; impermeabilização das superfícies; sem vegetação original e fauna/flora nativa; áreas industriais.

A identificação dos graus por meio das imagens foi feita em itens que possuem áreas representativas ao serem analisadas, como casas, fragmentos 


\section{ESTUDO DA ALTERAÇÃO ANTRÓPICA (HEMEROBIA) DA BACIA HIDROGRÁFICA DO}

RIO MOURÃO - PR

florestais, indústrias, prédios, entre outros. Sendo assim, os graus de hemerobia definidos podem ser compreendidos conforme quadro 2.

\begin{tabular}{|c|l|}
\hline Grau de Hemerobia & \multicolumn{1}{|c|}{ Descrição } \\
\hline Mínimo & $\begin{array}{l}\text { áreas de unidades de conservação, áreas de } \\
\text { preservação permanente e fragmentos florestais }{ }^{1} .\end{array}$ \\
\hline Muito baixo & $\begin{array}{l}\text { áreas com silvicultura e áreas de lazer (praças e parques } \\
\text { urbanos }{ }^{2} \text { ). }\end{array}$ \\
\hline Baixo & $\begin{array}{l}\text { áreas com mata devastada devido à interferência } \\
\text { antrópica (geralmente áreas abandonadas), vegetações } \\
\text { rasteiras e arbustos. }\end{array}$ \\
\hline Médio & $\begin{array}{l}\text { áreas utilizadas para agricultura, pecuária e solo exposto } \\
\text { e áreas preparadas para futuras construções civis. }\end{array}$ \\
\hline Alto & $\begin{array}{l}\text { áreas com construções civis de pequeno porte (casas) e } \\
\text { construções espaçadas, ambas com jardins ou presença } \\
\text { de arbustos e herbáceas. }\end{array}$ \\
\hline Muito alto & $\begin{array}{l}\text { áreas com calçadas, asfalto, centros comerciais, } \\
\text { construções civis e públicas de médio e grande porte } \\
\text { (prédios), podendo conter jardins, arbustos e árvores } \\
\text { espalhadas. }\end{array}$ \\
\hline Máximo & áreas industriais e usinas hidrelétricas \\
\hline
\end{tabular}

Quadro 2: Definição dos graus de Hemerobia.

De posse da caracterização da área de estudo, das informações sobre uso e ocupação do solo (dados de 2011) e da definição dos graus de hemerobia, foi feita a definição da hemerobia na bacia de forma quantitativa, por meio do uso do software Spring 5.2.7 (INPE, 1996).

Já para detalhar os graus de hemerobia da bacia, optou-se em fazer uma análise qualitativa ${ }^{3}$ considerando o recorte espacial de unidades de paisagem, conforme a delimitação feita por Scipioni (2014). A escolha da

\footnotetext{
${ }^{1}$ Fragmentos florestais: fragmentos de mata com dossel fechado e denso e interferência antrópica baixa ou inexistente.

2 Parques Urbanos: unidades de conservação na categoria de manejo de Parque que apresentam características de fluxo de pessoas de forma contínua e não controlada, localizado em áreas urbanas.

${ }^{3}$ Não foi possível quantificar os graus de hemerobia por unidade de paisagem, optando-se assim, pela análise qualitativa.
} 


\section{ESTUDO DA ALTERAÇÃO ANTRÓPICA (HEMEROBIA) DA BACIA HIDROGRÁFICA DO \\ RIO MOURÃO - PR}

aplicação dos graus considerando as unidades de paisagem teve como objetivo facilitar a compreensão dos resultados, tendo em vista o enfoque do estudo em projetos de planejamento para a área de estudo. Scipioni (2014) definiu as unidades de paisagem considerando as características de geologia e declividade da bacia, conforme pode ser visualizado na Figura 2. O tamanho das unidades corresponde: unidade $1-206,9 \mathrm{~km}^{2}$; unidade $2-418,9 \mathrm{~km}^{2}$; unidade $3-781,6 \mathrm{~km}^{2}$; unidade $4-241,2 \mathrm{~km}^{2}$.

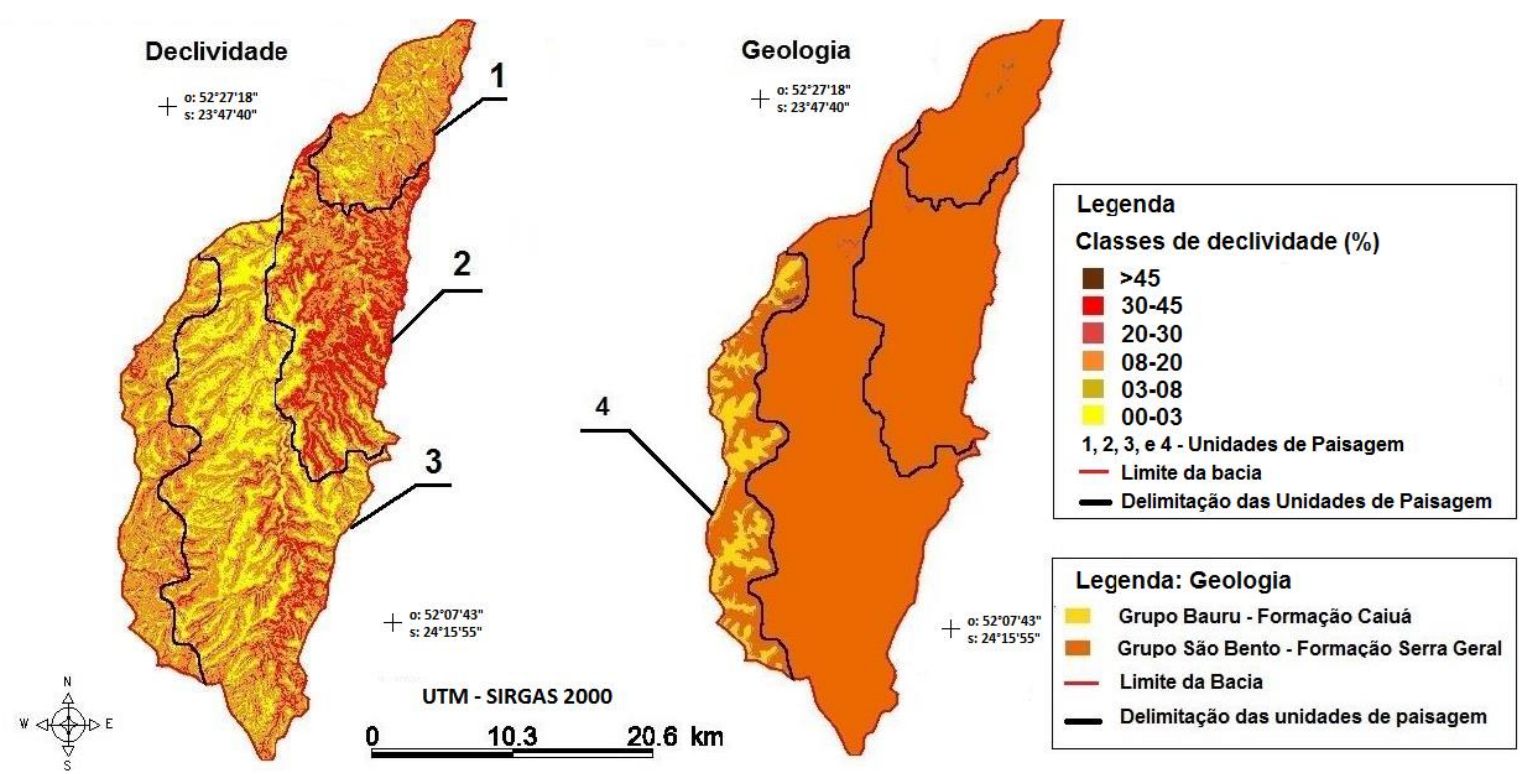

Figura 2: Divisão da bacia hidrográfica do rio Mourão em unidades de paisagem. Fonte: Scipioni (2014).

A análise qualitativa da hemerobia de cada unidade de paisagem foi desenvolvida utilizando o software Google Earth (2013) e trabalhos de campo. Foram definidas altitudes para capturar as imagens de referência de acordo com os graus para facilitar a visualização, assim sendo: 23 a $25 \mathrm{~km}$ para grau mínimo; $4 \mathrm{~km}$ para grau muito baixo; $3 \mathrm{~km}$ para grau baixo; $5 \mathrm{~km}$ para grau médio; $2 \mathrm{~km}$ para grau alto; e 2 a $3 \mathrm{~km}$ para grau muito alto e máximo. 


\section{ESTUDO DA ALTERAÇÃO ANTRÓPICA (HEMEROBIA) DA BACIA HIDROGRÁFICA DO RIO MOURÃO - PR}

\section{RESULTADOS E DISCUSSÕES}

O resultado para todos os graus de hemerobia podem ser conferidos na Tabela 1, a qual apresenta o predomínio do grau médio de hemerobia, ocupando $85,26 \%$ do total de $1.814,73 \mathrm{~km}^{2}$. A distribuição espacial dos graus de hemerobia pode ser visualizada na Figura 3.

Tabela 1: Total de área e porcentagem dos graus de hemerobia da bacia hidrográfica do rio Mourão - PR

\begin{tabular}{ccc}
\hline Grau & Área $\left.\mathbf{( k m}^{2}\right)$ & Porcentagem (\%) \\
\hline Mínimo & 141,59 & 7,8 \\
Muito Baixo & 22,84 & 1,26 \\
Baixo & 62,96 & 3,47 \\
Médio & $1.547,30$ & 85,26 \\
Alto & 37,00 & 2,04 \\
Muito Alto & 2,53 & 0,14 \\
Máximo & 0,50 & 0,03 \\
Total & $1.814,73$ & 100 \\
\hline
\end{tabular}

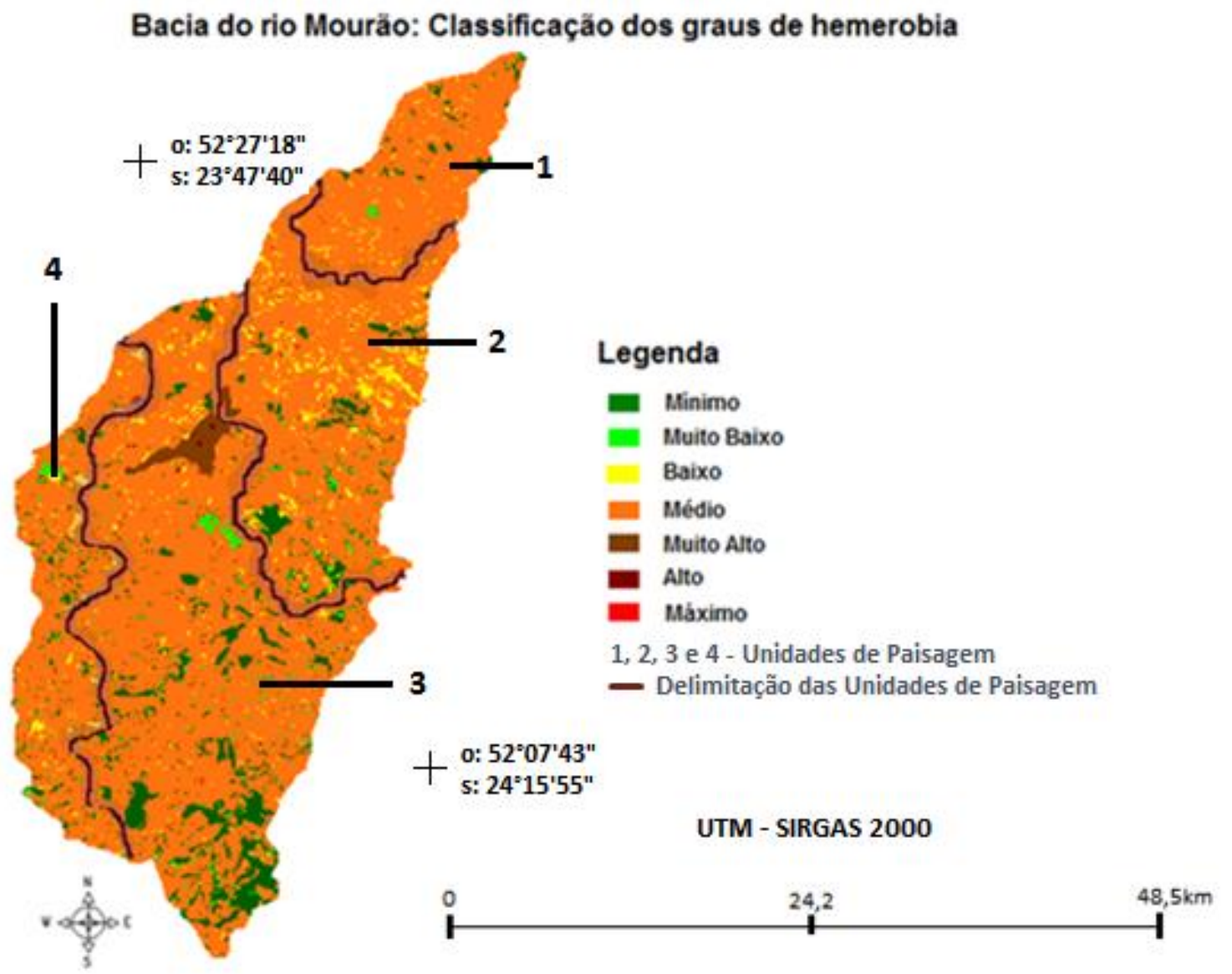

Figura 3: Distribuição dos graus de hemerobia na bacia hidrográfica do rio Mourão - PR. 


\section{ESTUDO DA ALTERAÇÃO ANTRÓPICA (HEMEROBIA) DA BACIA HIDROGRÁFICA DO RIO MOURÃO - PR}

A distribuição possibilita verificar que a presença dos graus alto, médio e baixo demonstra uma relação direta com o perfil econômico dos municípios da bacia.

De acordo com Carneiro (2014), o solo da bacia hidrográfica do rio Mourão é coberto por $70,4 \%$ de agropecuária, $0,3 \%$ de silvicultura, $24 \%$ de florestal, $0,9 \%$ de água e $1,4 \%$ de área urbana. Em relação às atividades agropecuárias, que ocupam a maior parte, dados do IPARDES (2012) indicam que os municípios que abrangem a bacia produzem principalmente soja, milho, trigo, mandioca, cana de açúcar e a criam bovinos, equinos, galináceos, ovinos e suínos.

Esta situação corrobora com Kröker (2008), quando este destaca que quanto maior for a hemerobia, distintas situações acontecem nos sistemas ambientais como a pouca conexão com a dinâmica dos valores naturais com significativa diminuição da vegetação original, bem como fauna/flora nativa.

Outro aspecto de destaque se refere ao grau mínimo de dependência tecnológica e energética para a manutenção da funcionalidade ambiental, que soma $7,8 \%$, sendo a segunda maior classe encontrada. Este valor é significativo diante do contexto deste estudo, uma vez que permite verificar o potencial conservador presente na bacia, o que pode, em um eventual projeto de planejamento, indicar áreas que podem ser destinadas à conservação da natureza, em comparação com outras que podem ser indicadas para atividades de exploração econômica.

Já em relação aos graus muito alto e máximo, percebe-se que estes não ocupam muitas áreas da bacia se comparada aos outros graus, porém não por isso se tornam menos importantes diante da análise da hemerobia, uma vez que apresentam considerável estado de dependência energética e tecnológica.

A hemerobia na bacia pode ser compreendida também quando analisadas de forma qualitativa, considerando como recorte espacial as unidades de paisagem, a saber.

a) Unidade de Paisagem 1: Nesta unidade de paisagem, foi possível encontrar todos os graus de hemerobia. O grau de hemerobia mínimo conta 


\section{ESTUDO DA ALTERAÇÃO ANTRÓPICA (HEMEROBIA) DA BACIA HIDROGRÁFICA DO \\ RIO MOURÃO - PR}

com áreas com fragmentos florestais localizados em beiras de rio, topo de morros ou isolados e uma Reserva Particular do Patrimônio Natural - RPPN, no município de Quinta do Sol. No grau muito baixo, foi possível encontrar áreas com silvicultura, verificadas em propriedades rurais pela uniformidade no tamanho das copas. Também foram verificadas áreas com mata devastada, possuindo vazios arbóreos, vegetações rasteiras e arbustos. O grau de hemerobia classificado como médio corresponde a áreas de agricultura como soja, milho, cana de açúcar, mandioca e pecuária, intercalado com fragmentos florestais isolados. O grau de hemerobia alto abrange a parte urbana do município de Engenheiro Beltrão, com construções civis de pequeno porte e residências isoladas nas propriedades rurais. Já no grau muito alto foram encontradas algumas construções de médio porte. Nesta unidade de paisagem há ainda, indústrias, classificadas como grau máximo conforme demonstra a matriz de classificação da unidade de paisagem 1 (Figura 4). 


\section{ESTUDO DA ALTERAÇÃO ANTRÓPICA (HEMEROBIA) DA BACIA HIDROGRÁFICA DO \\ RIO MOURÃO - PR}

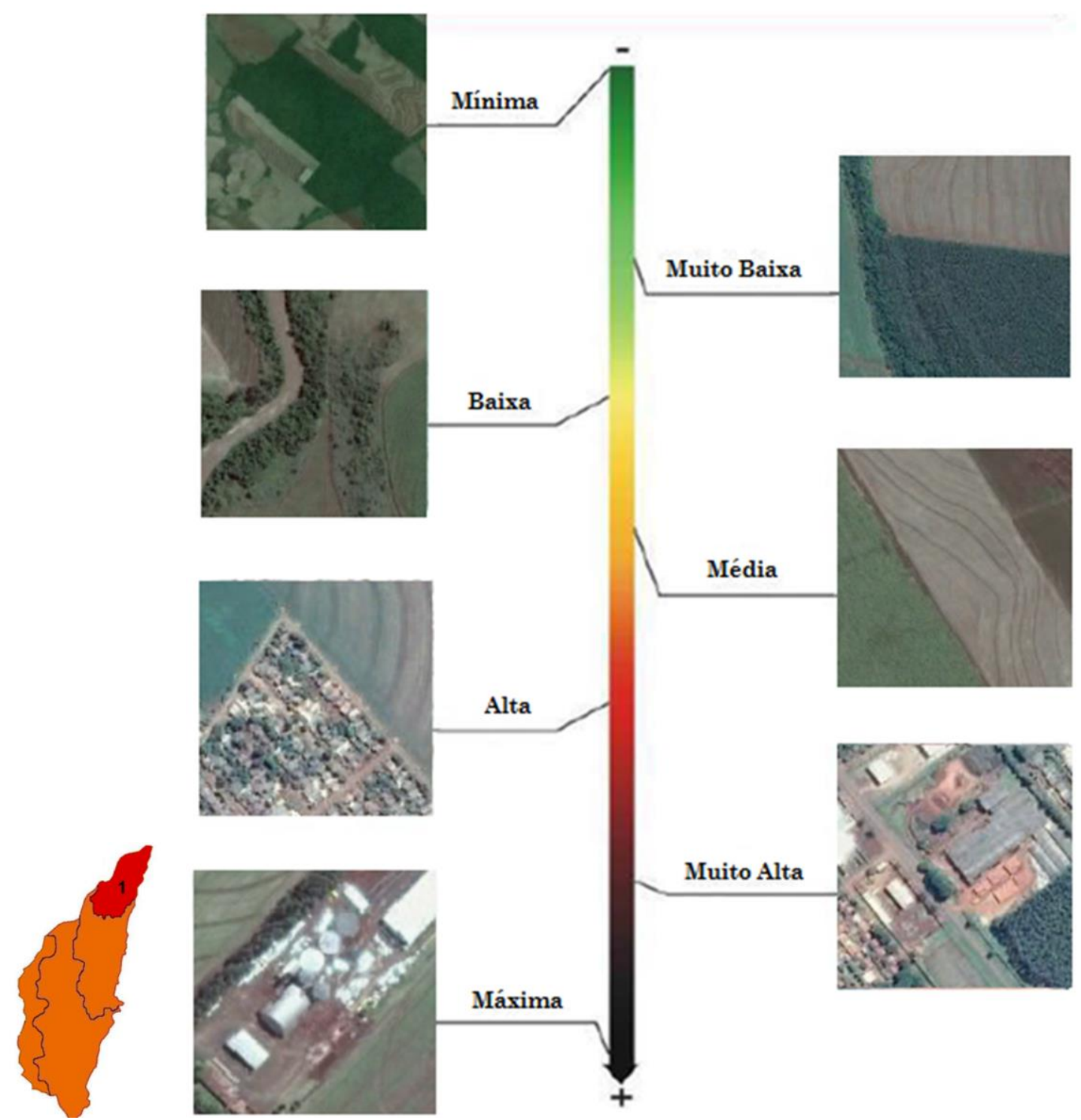

Figura 4: Matriz de classificação dos graus de hemerobia da unidade de paisagem 1 da bacia hidrográfica do rio Mourão - PR.

Fonte: Google Earth (2013).

b) Unidade de Paisagem 2: Esta unidade compreende parte dos municípios de Peabiru e Campo Mourão, que de acordo com as informações do IPARDES (2012), produzem soja, milho, mandioca e trigo. O grau mínimo possui fragmentos florestais e parte da Unidade de Conservação Parque Estadual Lago Azul. Há presença maior de fragmentos florestais nesta unidade quando comparados à unidade 1, os quais se localizam em Áreas de Preservação Permanente - APP e em morros com declividades acentuadas (média vertente). $\mathrm{O}$ grau de hemerobia muito baixo possui áreas de silvicultura e 0 


\section{ESTUDO DA ALTERAÇÃO ANTRÓPICA (HEMEROBIA) DA BACIA HIDROGRÁFICA DO \\ RIO MOURÃO - PR}

grau baixo possui áreas de mata devastada com presença de vegetações rasteiras e arbustos. A classificação do grau de hemerobia médio envolve áreas de cultivo agrícola, assim como áreas com solo exposto e pastagem. $\mathrm{Na}$ parte urbana do município de Peabiru há presença de casas, classificando-a como grau alto. Já as construções de médio e grande porte como depósitos, ginásios, entre outros, a classificação da hemerobia é de grau muito alto. No grau de hemerobia máximo, há presença de áreas de produção isoladas, sendo pouco encontradas, assim como na Unidade de Paisagem 1. Por meio da classificação dos graus de hemerobia, foi possível verificar que a unidade de paisagem 2 possui representatividade em relação aos fragmentos florestais e que a concentração de área urbana é visivelmente menor quando comparada com as unidades 1 e 3 (Figura 5). 


\section{ESTUDO DA ALTERAÇÃO ANTRÓPICA (HEMEROBIA) DA BACIA HIDROGRÁFICA DO RIO MOURÃO - PR}

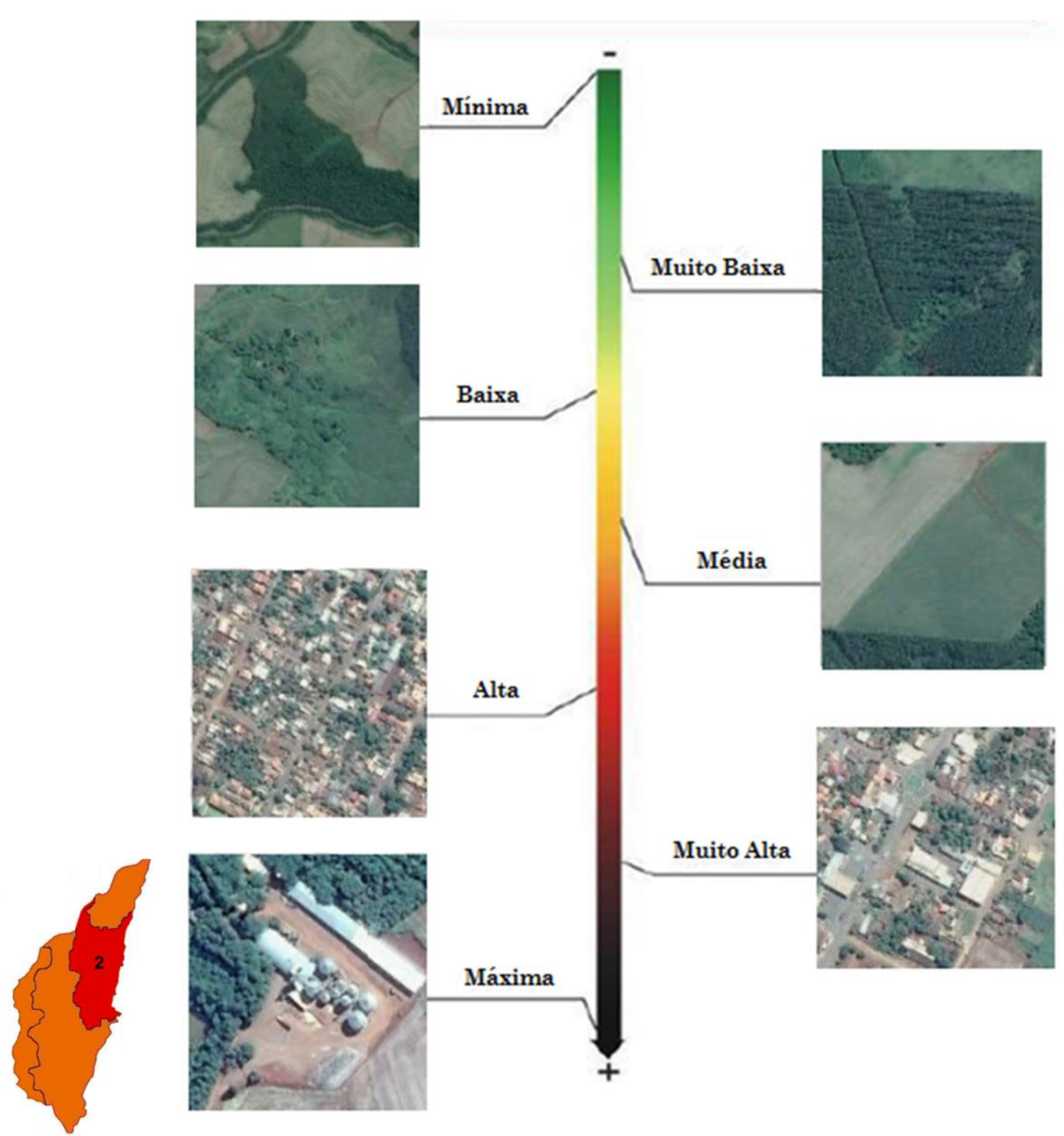

Figura 5: Matriz de classificação dos graus de hemerobia da unidade de paisagem 2 da bacia hidrográfica do rio Mourão - PR.

Fonte: Google Earth (2013).

c) Unidade de Paisagem 3: Envolve parte dos municípios de Campo Mourão e Luiziana-PR, sendo sede da área urbana e industrial do município de Campo Mourão. Nesta unidade há maior quantidade de Unidades de Conservação em relação às outras unidades de paisagem, sendo seis, uma estação ecológica, dois parques municipais e parte do Parque Estadual Lago Azul todos 


\section{ESTUDO DA ALTERAÇÃO ANTRÓPICA (HEMEROBIA) DA BACIA HIDROGRÁFICA DO RIO MOURÃO - PR}

localizados em Campo Mourão. Além disso, conta com áreas de preservação permanente no entorno do reservatório da Usina Hidrelétrica Mourão I e em outros rios. Todas as Unidades de Conservação descritas (exceto um Parque Municipal), áreas de preservação e fragmentos florestais foram classificadas como grau mínimo. As áreas de lazer como praças e o Parque Municipal Joaquim Teodoro de Oliveira em Campo Mourão, foram classificados como grau de hemerobia muito baixo devido ao fluxo de pessoas que passa diariamente, não apresentando limite. Ainda na hemerobia muito baixa, há presença de áreas de silvicultura. A presença de mata devastada é perceptível pelas imagens de satélite sendo classificadas como grau de hemerobia baixo. Já no grau de hemerobia médio, por conter parte de área urbana, há maior quantidade de áreas com solo exposto que estariam sendo preparadas para futuras construções civis. Conforme dados do IPARDES (2012), Campo Mourão e Luiziana produzem soja, milho e trigo, além da criação de bovinos, equinos, galináceos, ovinos e suínos, predominando agricultura nesta unidade. A maior parte da área urbana de Campo Mourão, devido à grande quantidade de casas construídas, aos centros comerciais, prédios e outros estabelecimentos classificados como construções civis de médio e grande porte, foi classificada como grau de hemerobia alto e muito alto. Nesta unidade há também maior concentração de indústrias em relação as outras unidades, localizadas, em sua maioria no município de Campo Mourão. Estas áreas foram classificadas como grau máximo de hemerobia. Além das indústrias há atividades de mineração, e a presença de uma usina hidrelétrica (Mourão I) e uma pequena central hidrelétrica ( $\mathrm{PCH}$ Salto Natal), também classificadas como grau máximo. Estes graus de hemerobia estão representados na Figura 6, com destaque para o grau máximo que entre as 4 unidades de paisagem, é a mais representativa. 


\section{ESTUDO DA ALTERAÇÃO ANTRÓPICA (HEMEROBIA) DA BACIA HIDROGRÁFICA DO RIO MOURÃO - PR}

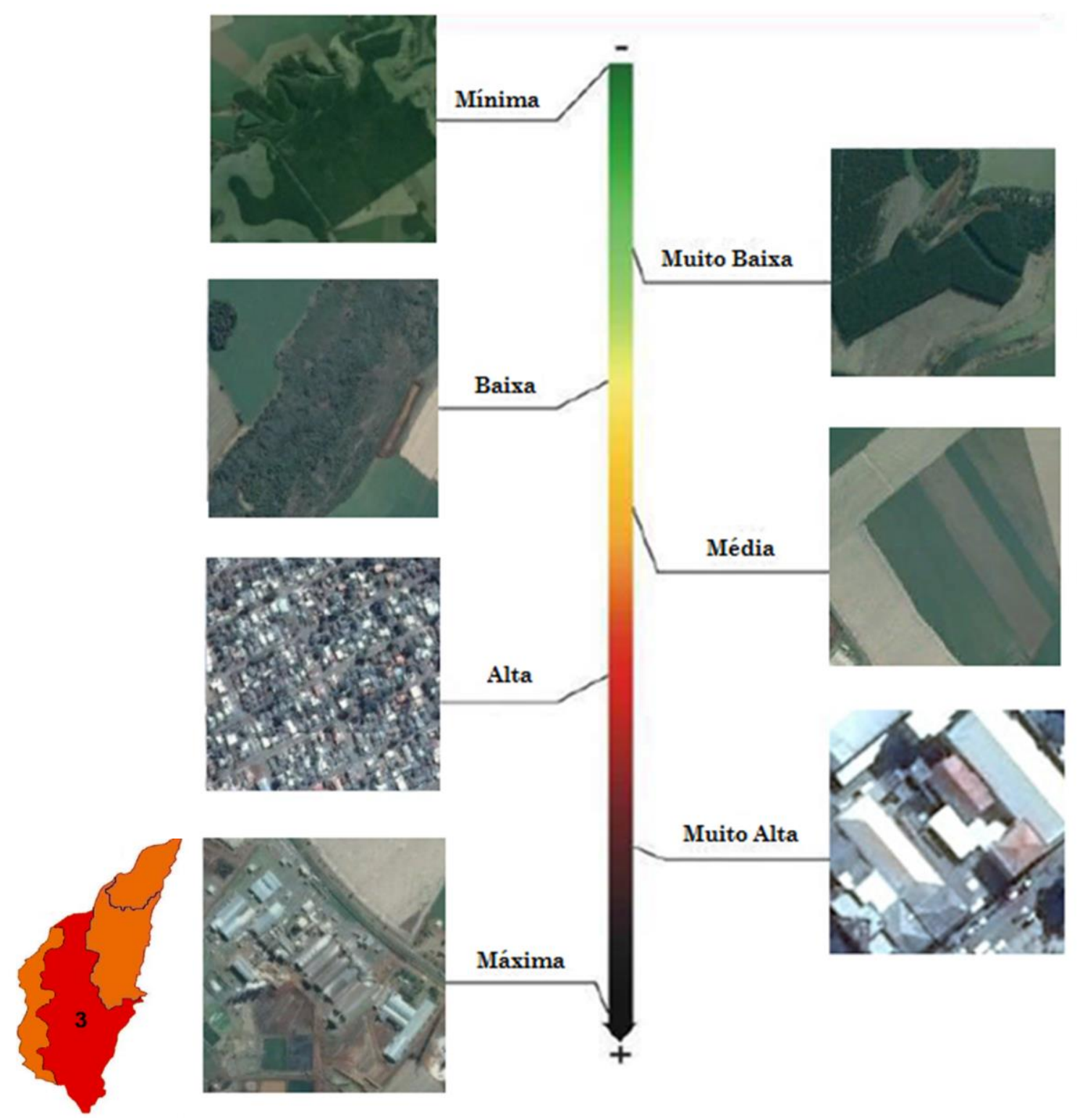

Figura 6: Matriz de classificação dos graus de hemerobia da Unidade de Paisagem 3 da bacia hidrográfica do rio Mourão - PR.

Fonte: Google Earth (2013).

d) Unidade de Paisagem 4: Abrange parte do município de Mamborê e o distrito de Piquirivaí (pertencente ao município de Campo Mourão). Na classificação do grau de hemerobia mínimo, assim como nas outras unidades, foram encontrados fragmentos florestais e uma RPPN. O grau de hemerobia baixo possui áreas com mata devastada, contendo arbustos e herbáceas. 


\section{ESTUDO DA ALTERAÇÃO ANTRÓPICA (HEMEROBIA) DA BACIA HIDROGRÁFICA DO RIO MOURÃO - PR}

Áreas de agricultura são predominantes nesta unidade, sendo classificadas como grau de hemerobia médio. As áreas de construções civis isoladas de pequeno e médio porte (silos) localizadas nas propriedades rurais e em um distrito de Campo Mourão foram classificadas como grau de hemerobia alto e muito alto. Esta unidade é a única que não apresenta o grau máximo de hemerobia (Figura 7).

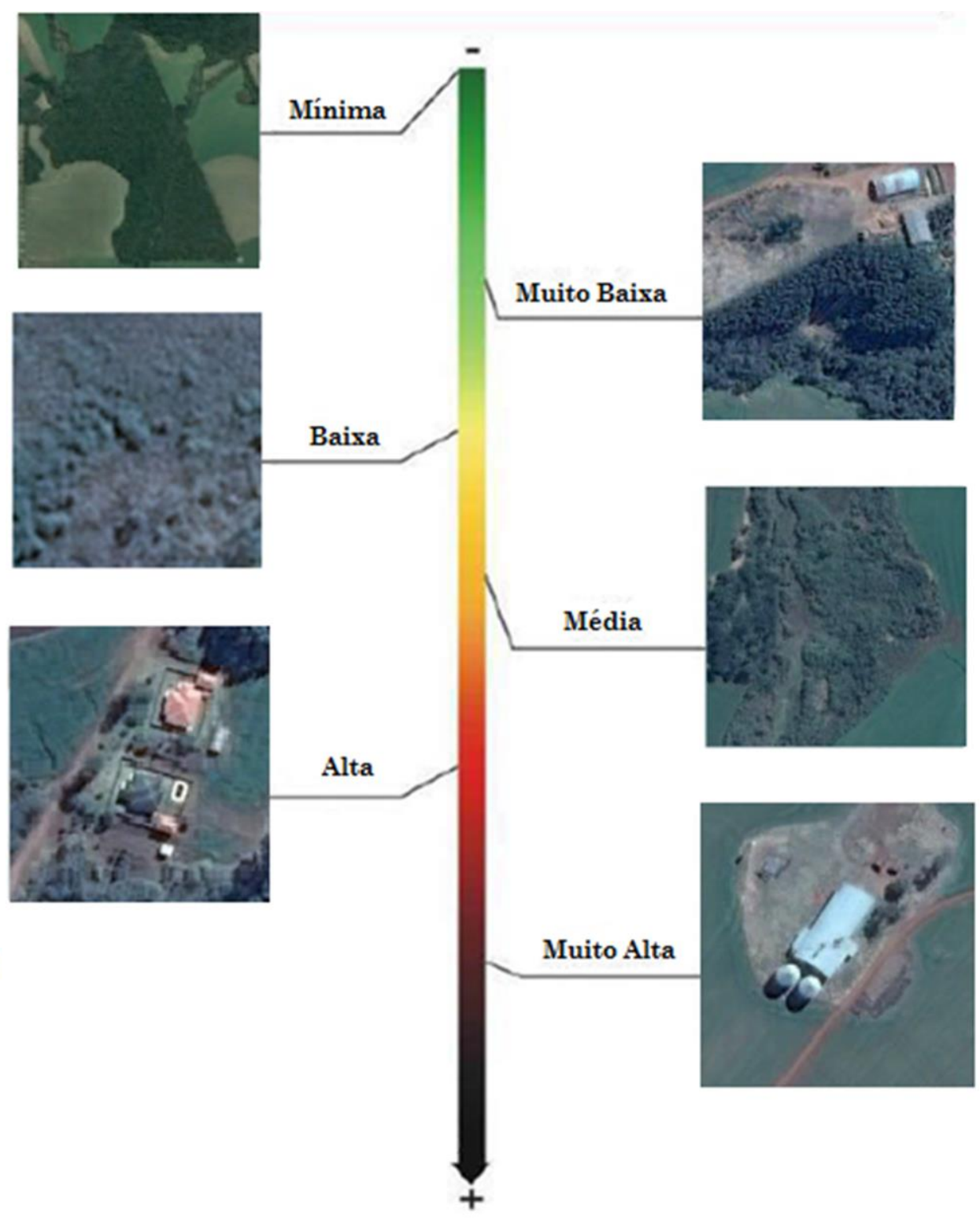

Figura 7: Matriz de classificação dos graus de hemerobia da Unidade de Paisagem 4 da bacia hidrográfica do rio Mourão - PR.

Fonte: Google Earth (2013). 


\section{ESTUDO DA ALTERAÇÃO ANTRÓPICA (HEMEROBIA) DA BACIA HIDROGRÁFICA DO RIO MOURÃO - PR}

Os resultados obtidos com a aplicação das matrizes de classificação da hemerobia destacam-se alguns aspectos, tais como:

- Na unidade de paisagem 1, há menos áreas com os graus alto, muito alto e máximo, quando comparadas a unidade de paisagem 3 que conta com mais áreas de grau alto. A presença destes graus é um indicativo de que o planejamento deve considerar as especificidades, independente do tamanho das áreas, uma vez que em maior ou menor escala, os impactos irão acontecer de alguma forma;

- A unidade de paisagem 2 possui relação direta entre o tipo de uso do solo e as características do relevo, uma vez que é a parte da bacia com maior declividade e as áreas destinadas para pastagem, silvicultura e fragmentos florestais estão em vertentes com declividade mais acentuada. Pode-se inferir que esta característica geomorfológica influencia no resultado dos graus de hemerobia encontrados na unidade, com destaque para o grau baixo, que se apresenta em maior quantidade se comparado as outras unidades, possivelmente devido às condições de declividade que não possibilitam o desenvolvimento de atividades como agricultura;

- A unidade de paisagem 3 se destaca em relação às outras unidades em todos os graus de hemerobia. Esta situação pode ser justificada pelo fato de ser a maior unidade e por abranger a área urbana do município de Campo Mourão - PR, que é a maior cidade dos seis municípios. Nesta unidade, os graus muito alto, alto e máximo se destacam em relação às demais unidades. Por outro lado, esta unidade também apresenta maior quantidade de áreas com grau mínimo e muito baixo de hemerobia devido à presença de vários fragmentos florestas e unidades de conservação. Esta situação leva a verificação de certa contradição, pois ao mesmo tempo em que é a área de menor declividade e com maior potencial agrícola de toda bacia (MEZZOMO, 2013), conta com o maior potencial conservador. Esta constatação se torna importante quando se pensa em políticas 


\section{ESTUDO DA ALTERAÇÃO ANTRÓPICA (HEMEROBIA) DA BACIA HIDROGRÁFICA DO RIO MOURÃO - PR}

públicas que consideram os limites e aptidões da paisagem, uma vez que em uma mesma unidade de paisagem se tem duas condições importantes a serem consideradas;

- Já na unidade de paisagem 4, destaca-se o grau médio devido a presença de agricultura que predomina enquanto uso do solo. Há também a presença, em menores proporções, do grau mínimo, devido as exigências legais de áreas de reserva legal e preservação permanente.

Estas variadas situações dos graus nas unidades de paisagem da bacia permitem verificar que cada grau é um indicativo de potencialidades a serem consideradas diante das atividades antrópicas. Ou seja, cada recorte espacial apresentará aptidões e limites distintos, permitindo assim direcionar ações específicas na paisagem, tendo em vista minimizar impactos e/ou potencializar as atividades econômicas.

\section{CONSIDERAÇÕES FINAIS}

O estudo dos graus de hemerobia na paisagem da bacia hidrográfica do rio Mourão possibilitou verificar que $85,26 \%$ da bacia apresentam grau médio, composto por áreas utilizadas para agricultura, pecuária e solo exposto. A segunda classe mais representativa na bacia soma $7,8 \%$ e se refere ao grau mínimo, com a presença de Unidades de Conservação, Áreas de Preservação Permanente e fragmentos florestais isolados.

Estas duas situações se destacam pela quantidade de área que ocupam, evidenciando em um primeiro momento, dois potenciais: um para as atividades agropecuárias e outro para a conservação. Para tanto, é preciso analisar de forma mais detalhada a localização e as condições em que estes usos estão sendo desenvolvidos para verificar se apresentam limites específicos que não potencializam suas funções, já que só a presença destes graus não é suficiente para elencar a qualidade do potencial.

Já a presença dos graus muito alto e máximo, como verificado nas unidades de paisagem 1, 2 e 3, demonstra que há necessidade de atenção por parte dos planejadores e gestões, devido às conseqüências que estas 


\section{ESTUDO DA ALTERAÇÃO ANTRÓPICA (HEMEROBIA) DA BACIA HIDROGRÁFICA DO \\ RIO MOURÃO - PR}

situações podem promover. Entre estas consequências destacam-se 0 potencial poluidor das áreas industriais, o aumento da impermeabilização que diminui as taxas infiltração nos centros urbanos, o aumento de construções sem considerar áreas verdes que pode promover alteração do microclima e diminuição da qualidade ambiental urbana, entre outros.

Em todos os graus de hemerobia, torna-se importante considerar as especificidades, uma vez que ao mesmo tempo em que a sociedade precisa utilizar dos elementos naturais para atender suas necessidades, os mesmos tem se tornados insuficientes diante dos problemas gerados pela própria sociedade, como contaminação, poluição, esgotamento de elementos naturais, além de outros inúmeros problemas.

Avaliar os graus de hemerobia de uma determinada paisagem pode assim, contribuir para o planejamento de ações que visam à melhoria da qualidade ambiental, possibilitando localizar onde estão e quais são as maiores modificação da paisagem e seus motivos, facilitando a tomada de medidas para o manejo adequado nas práticas de agricultura e pecuária, bem como na ocupação planejados nas áreas urbanas.

\section{REFERÊNCIAS}

BERTRAND, G. Paisagem e geografia física global. Esboço metodológico. $13^{\circ}$ Caderno de Ciências da Terra. USP, Instituto de Geografia. Tradução: Olga Cruz. São Paulo, 1971.

CARNEIRO, M. G. Classificação da vulnerabilidade geoambiental e levantamento do uso e ocupação do solo da bacia do rio Mourão Paraná. 2014. Trabalho de Conclusão de Curso (Graduação em Engenharia Ambiental) - coordenação de Engenharia Ambiental, Universidade Tecnológica Federal do Paraná, Campo Mourão.

EMBRAPA - EMPRESA BRASILEIRA DE PESQUISA AGROPECUÁRIA. Levantamento de Reconhecimento dos Solos do Estado do Paraná. Articulação: Ml - 505. Ministério da Agricultura, Pecuária e Abastecimento. Brasil, 2007. Escala 1:250.000. Disponível em: <http://www.infoteca.cnptia.embrapa.br/bitstream/doc/339505/12/MI505.pdf>. Acesso em: 05 fev. 2014. 


\section{ESTUDO DA ALTERAÇÃO ANTRÓPICA (HEMEROBIA) DA BACIA HIDROGRÁFICA DO \\ RIO MOURÃO - PR}

FÁVERO, O. A.; NUCCI, J. C.; BIASI, M. de Hemerobia nas unidades de paisagem da Floresta Nacional de Ipanema, Iperó/SP: conceito e método. In: VI CONGRESSO BRASILEIRO DE UNIDADES DE CONSERVAÇÃO, 6, 2004, Curitiba. Anais... Curitiba: Fundação $O$ Boticário de Proteção à Natureza, v. 1, p. 550-559, 2004. Disponível em: <http://www.labs.ufpr.br/site/wpcontent/uploads/2014/07/favero_anaisdecongressos_cbuc_2004.pdf>. Acesso em: Acesso em: 10 fev. 2014.

FREITAS, A. R. A repercussão da legislação na dinâmica do uso da terra na bacia do rio Cará-Cará, Ponta Grossa- PR, no período de 1980 a 2007. 2008. Dissertação (Mestrado em Gestão de Território) - UEPG, Setor de Ciências exatas e naturais- Departamento de Geociências. Ponta Grossa.

GOOGLE EARTH - Imagens do software, 2013.

HABER, W. Using Landscape Ecology in Planning and Management. In: ZONNEVELD, I.S.; FORMAN, R.T.T. (Eds.) Changing Landscapes: an ecological perspective. New York: Springer-Verlag, 1990, 286p.

HOUGH, M. Naturaleza y ciudad. Planificación y procesos ecológicos. Barcelona: Gustavo Gili, 1995, 315p.

IBGE - INSTITUTO BRASILEIRO DE GEOGRAFIA E ESTATÍSTICA. Sinopse do Censo Demográfico 2010. Rio de Janeiro, 2010. Disponível em: $<$ http://www.censo2010.ibge.gov.br/sinopse/index.php?uf=41\&dados $=0$ > . Acesso em: 13 dez. 2013.

INPE, Instituto Nacional de Pesquisas Espaciais. SPRING: Integrating remote sensingand GIS by object-oriented data modelling" Camara G, Souza RCM, Freitas UM, Garrido J Computers \& Graphics, 20: (3) 395-403, May-Jun 1996. Disponível em: <http://www.dpi.inpe.br/spring/portugues/index.html>. Acesso em: 20 set. 2013.

ITCG - INSTITUTO DE TERRAS, CARTOGRAFIA E GEOCIÊNCIAS. Formações fitogeográficas - Estado do Paraná. 2009. Escala 1:2.000.000. Disponível em: <http://www.itcg.pr.gov.br/arquivos/File/Produtos_DGEO/Mapas_ITCG/PDF/Ma pa_Fitogeografico_A3.pdf>. Acesso em: 28 mar. 2014.

IPARDES - INSTITUTO PARANAENSE DE DESENVOLVIMENTO ECONÔMICO E SOCIAL. Perfil dos Municípios. Curitiba, 2012. Disponível em: $<$ ttp://www.ipardes.gov.br/index.php?pg_conteudo=1\&cod_conteudo=29>. Acesso em: 27 set. 2014.

JALAS, J. Hemerobe und hemerochore pflanzenarten. Acta Soc. Pro fauna et flora. $72, n^{\circ} 11,1955$. 
KRÖKER, R.; NUCCI, J. C.; MOLETTA, I. M. O conceito de hemerobia aplicado ao planejamento de paisagens urbanizadas. In: INTERNATIONAL CONGRESS ON ENVIRONMENTAL CHALLENGES OF URBANIZATION. 2005, Brasília. Anais... Brasília: 2005. 1 CD-ROM. Disponível em: <http://www.geografia.ufpr.br/laboratorios/labs/arquivos/kroker-et-al-2005.pdf>. Acesso em: 12 fev. 2014.

KRÖKER, R. Transformação da paisagem e estado hemerobiótico do bairro de Santa Felicidade, Curitiba/PR. 2008. Dissertação (Mestrado em Geografia) - UFPR, Setor de Ciências da Terra. Curitiba.

LABGEO, Laboratório de Geoprocessamento. Cartas Temáticas da bacia do rio Mourão. Escala 1:50.000, dados SRTM, 2000, imagens Landsat 5 - TM, cena 223/76 e 223/77. Universidade Tecnológica Federal do Paraná, campus Campo Mourão. 20 de jun 2013.

MEZZOMO, M. D. M. Planejamento da paisagem e conservação da natureza em RPPNs na bacia hidrográfica do rio Mourão, Paraná. 2013. Tese (Doutorado em Geografia) - Setor de Ciências da Terra, Universidade Federal do Paraná, Curitiba.

MINEROPAR - Minerais do Paraná S.A. Atlas geomorfológico. Escala base 1:500.000. Curitiba, 2006.

MINEROPAR - Minerais do Paraná S.A. Geologia do Paraná. Escala 1:650.000, Curitiba, 2005.

MINEROPAR - Minerais do Paraná S.A. Carta Geológica de Campo Mourão, escala 1:250.000, 2006.

MONTEIRO, C. A. F. Derivações antropogênicas dos geossistemas terrestres no Brasil e alterações climáticas: perspectivas urbanas e agrárias ao problema da elaboração de modelos de avaliação. SIMPÓSIO SOBRE A COMUNIDADE VEGETAL COMO UNIDADE BIOLÓGICA, TURÍSTICA E ECONÔMICA. Anais... São Paulo: ACIESP no15, 1978, p. 43-74.

SCIPIONI, B. Identificação de áreas prioritárias para conservação da natureza na bacia do rio Mourão - PR. 2014. Trabalho de Conclusão de Curso (Graduação em Engenharia Ambiental) - coordenação de Engenharia Ambiental, Universidade Tecnológica Federal do Paraná, Campo Mourão.

SUKOPP, H. Wandel von Flora und Vegetation in Mitteleuropa unter dem Einfluss dês Menschen. Berichte uber Landwirtschaft, Bd. 50/H.1: 112-139, 1972.

TROPPMAIR, H. Biogeografia e Meio Ambiente. Rio Claro: edição do autor, 1989, 258p. 